\title{
Promovendo a AUtonomia SOCIOCUltural DE PROFESSORES DE INGLÊS EM FORMAÇ̃̃O INICIAL NO CONTEXTO PIBID/CAPES*
}

Fernanda Passos da Trindade Jorge NERES ${ }^{* *}$

Christine NICOLAIDES ${ }^{* * *}$

\section{RESUMO}

A partir da observação e análise de um contexto de pesquisa do subprojeto LetrasInglês/UFRJ do PIBIB/CAPES verificou-se que os licenciandos, ao invés de se guiarem apenas por tarefas definidas pelo coordenador, se responsabilizavam pelo trabalho, ocorrendo um equilíbrio no que se refere à tomada de decisões entre esses participantes do projeto. Sendo assim, este trabalho tem como objetivo compreender a promoção da autonomia sociocultural (OXFORD, 2003), por parte desses licenciandos envolvidos no projeto, trazendo à tona alguns exemplos de como a condução desse Projeto PIBID se deu ao longo das reuniões pedagógicas e como esse equilíbrio na tomada de decisões se reflete, na sala de aula, quando esses licenciandos passam então a atuar como professores.

PalaVRas-ChaVE: autonomia sociocultural, formação inicial de professores, ensino de línguas.

\section{INTRODUÇ̃̃̃O}

Ao propor uma investigação sobre a promoção da autonomia em um contexto de ensino-aprendizagem de língua inglesa, torna-

* Programa Institucional de Bolsa de Iniciação à Docência da Comissão de Aperfeiçoamento de Pessoal do Nível Superior.

** Mestre em Linguística Aplicada pela Universidade Federal do Rio de Janeiro (UFRJ), Rio de Janeiro, Brasil. E-mail: fernandaptjn@yahoo.com.br

*** Doutora em Letras pela Universidade Federal do Rio Grande do Sul (UFRGS), Porto Alegre, Rio Grande do Sul, Brasil. Professora Associada na Universidade Federal do Rio de Janeiro (UFRJ), Rio de Janeiro, Brasil. E-mail: christine.nicolaides@gmail.com 
se vital compreender a visão de autonomia abordada por este trabalho. Sendo assim, para iniciar essa reflexão sobre o conceito de autonomia, vale citar Paulo Freire (1996, p. 59-60, grifo nosso) ao afirmar que

Outro saber necessário à prática educativa [...] é o que fala do respeito devido à autonomia do ser do educando. Do educando criança, jovem ou adulto. [...] $\mathbf{O}$ respeito à autonomia e à dignidade de cada um é um imperativo ético e não um favor que podemos ou não conceder uns aos outros. [...] O professor que desrespeita a curiosidade do educando, o seu gosto estético, a sua inquietude, a sua linguagem, mais precisamente, a sua sintaxe e a sua prosódia: o professor que ironiza o aluno, que o minimiza, que manda que 'ele se ponha em seu lugar' ao mais tênue sinal de sua rebeldia legítima, tanto quanto o professor que se exime do cumprimento de seu dever de propor limites à liberdade do aluno, que se furta ao dever de ensinar, de estar respeitosamente presente à experiência formadora do educando, transgride os princípios fundamentalmente éticos de nossa existência.

A citação de Freire indica que autonomia não está associada necessariamente a questões relacionadas a alunos autodidatas, ou a estratégias para que ele ou ela estude sozinho, sem o auxílio de um professor. Pelo contrário, as palavras do autor direcionam para o entendimento de que o desenvolvimento de autonomia pode significar a construção de um forte laço entre professores e alunos, laço esse que se fundamenta principalmente no respeito mútuo.

Pensar sobre autonomia na área da educação não é algo recente, muito pelo contrário. Rousseau, em 1762, em sua obra Emílio, de certa forma já abordava ao propor um novo modelo de educação que deveria seguir os impulsos e inclinações do aprendiz. Adicionalmente, Rousseau tinha uma visão de educação que priorizava a formação de um cidadão para o mundo em detrimento da uma formação conteudista. Ele afirmou:

pouco me importa que destinem meu aluno à espada, à Igreja ou à barra. Antes da vocação dos pais, a natureza o chama para a vida humana. Viver é o ofício que quero ensinar-lhe. Ao sair de minhas mãos, concordo que não será nem magistrado, nem soldado, nem 
padre; será homem, em primeiro lugar; tudo o que o homem deve ser, ele será capaz de ser, se preciso, tão bem quanto qualquer outro; e, ainda que a fortuna o faça mudar de lugar, ele sempre estará no seu. Nosso verdadeiro estudo é a condição humana (ROUSSEAU, 2004, p. 14-15).

Dando um salto no tempo e versando especificamente sobre o ensino-aprendizagem de línguas, foco deste trabalho, Benson (1997) propõe um modelo com três versões para a autonomia do aprendiz. Essas versões (técnica, psicológica e política) estão relacionadas a teorias do conhecimento e da aprendizagem (positivismo, construtivismo e teoria crítica). Segundo Benson, a versão técnica de autonomia estaria relacionada a treinar o aluno com técnicas e estratégias para que ele possa atuar em situações de aprendizagem na qual ele não tenha o suporte de um professor.

A versão psicológica define autonomia como uma capacidade, ou seja, uma construção de atitudes e habilidades, que acabam favorecendo para que o aluno se responsabilize pelo seu aprendizado. Essa versão entra em consonância com o construtivismo visto que da mesma forma que a autonomia é construída, a língua, nesta visão, também é construída pelo aprendiz na medida em que ele interage e negocia significado com a mesma. Assim, são os aprendizes que constroem sua língua e autonomia para o processo de ensino-aprendizagem.

Por fim, a versão política entende que autonomia está relacionada com o controle sobre o processo e conteúdo de aprendizagem. Em consonância com a teoria crítica, os alunos devem ser estimulados a conscientizar-se do contexto social de aprendizagem e de todas as restrições existentes, ou seja, o aluno deve ter voz para interferir no processo de ensino-aprendizagem. Benson (1997, p. 24) dá uma ênfase à abordagem política de autonomia e afirma que

a autonomia cresce na medida em que aprendizes se tornam mais críticos e conscientes do contexto social de aprendizagem e das restrições impostas por ele, do que é apresentado a eles como "língua alvo" e dos potencias para mudança social implícitos na aprendizagem de línguas. 
Esse modelo, apesar de inovador e de ter sido um marco na área de autonomia (NICOLAIDES, 2003; HUNTER; COOKE, 2007; MARTINEZ, 2008; PAIVA, 2008, entre outros) sofre críticas (OXFORD, 2003) principalmente no que diz respeito à ênfase apenas na versão política e a não inclusão de uma versão voltada para os aspectos sociais e culturais. Com o objetivo de expandir esse modelo de Benson (1997), Oxford (2003) propõe um novo modelo (quadro 1) para definir autonomia com quatro perspectivas, cada uma com um foco diferente.

Quadro 1: Resumo esquemÁtico DO MODELO DE AUTONOMIA PROPOSTO POR OXFORD (2003, P. 76).

\begin{tabular}{|l|l|}
\hline PersPectivas de Autonomia & Foco \\
\hline Técnica & Ambientação física \\
\hline Psicológica & Características dos aprendizes \\
\hline Sociocultural & Aprendizagem mediada \\
\hline Político-crítica & Ideologias, acesso e estruturas de poder. \\
\hline
\end{tabular}

Nesse modelo, a perspectiva técnica é preservada a partir do modelo de Benson (1997), cujo foco é na situação física, ou seja, autonomia é entendida como as habilidades necessárias para situações de "aprendizagem independente" (OXFORD, 2003, p. 77). Já a versão psicológica tem como foco as características individuais do aluno, sendo a autonomia uma combinação de características tais como, atitudes, habilidade, estratégias e estilos de aprendizagem.

A inovação desse modelo é a perspectiva sociocultural (sociocultural I e II) que foca no aprendizado mediado, posto que entende a interação social como parte essencial tanto do desenvolvimento cognitivo quanto do desenvolvimento da linguagem. Segundo a perspectiva sociocultural I, a autonomia é entendida como a autorregulação adquirida através da interação social com um par mais experiente. Já a perspectiva sociocultural II não tem como meta principal a autonomia e sim a participação do indivíduo na sua comunidade de prática. Participação essa que, inicialmente, se dá de forma periférica e com o passar do tempo adquire um papel central. 
Oxford fundamenta seu modelo nos pressupostos da teoria sociocultural (TSC) e aprendizagem de segunda língua de Lantolf (2000), que por sua vez se baseia nos trabalhos de Vigotski (2007, 2008, 2010). Entre os princípios da TSC encontra-se o entendimento de que a interação promove o desenvolvimento da capacidade humana e que a aprendizagem mediada é significativa e situada no tempo e espaço.

Assim sendo, as perspectivas de autonomia sociocultural I e II de Oxford (2003) parecem reforçar a ideia de que no processo de ensinoaprendizagem, aprendizes e professores devem estar engajados em atividades significativas para que exista motivação, interesse e sucesso no processo de ensino-aprendizagem.

Por fim, a versão político-crítica tem como foco ideologia, acesso e estruturas de poder. Segundo Oxford (2003), a autonomia está relacionada à capacidade para conseguir acesso a alternativas culturais e a estruturas de poder, assim como a capacidade de ter voz entre diversas ideologias em competição. De acordo com Norton (2000), o poder não opera apenas no nível institucional macro, mas também nos microencontros do dia a dia. Oxford (2003) conclui que "podemos analisar de forma crítica os discursos que enquadram nossas vidas, podemos criar novas alternativas e podemos desafiar nossos alunos a fazer o mesmo" (OXFORD, 2003, p. 90).

Com esse modelo, Oxford enfatiza e traz à tona, a importância de incluir nos estudos sobre autonomia no ensino-aprendizagem de línguas a questão social. É necessário ter em mente que o aprendizado é mediado e socialmente construído, assim a autonomia nesse processo necessariamente deve ser entendida dentro do contexto social em questão. Oxford (2011) ainda acrescenta que de nada adianta o aprendiz possuir habilidade, atitude, vontade e ação se ele entende o mundo apenas sob uma perspectiva individual. Segundo ela, a ideia de uma autonomia individual é insuficiente, já que o mundo é coletivo. Para Oxford, alunos de línguas estrangeiras autônomos devem ser "ativos, reflexivos e responsáveis em diversos contextos sociais" (p. 237). Nesse mesmo sentido, Pennycook (1997) faz uma forte crítica à concepção individual de autonomia, que possa induzir a ideias de isolamento ou comportamento introvertido, falta de interação ou o fato de ignorar o contexto sociocultural (HUNTER; COOKE, 2007). 
Assim sendo, o objetivo deste trabalho é compreender a promoção da autonomia de professores em formação inicial ao longo da condução do subprojeto Letras-Inglês/UFRJ do PIBIB/CAPES que, ao trabalharem coletivamente, demonstram construir um ambiente bastante favorável à construção da autonomia, sob a perspectiva sociocultural e com uma visão crítica de ensino-aprendizagem ${ }^{1}$ da língua inglesa. Visão essa que compreende a função social da língua e o ambiente educativo como um espaço de emancipação pessoal e de transformação social.

\section{Metodologia}

\subsection{O CONTEXTO DE PESQUISA}

O PIBID, executado no âmbito da Coordenação de Aperfeiçoamento de Pessoal de Nível Superior - CAPES, tem como finalidade fomentar a iniciação à docência, contribuindo para o aperfeiçoamento da formação de docentes em nível superior e para a melhoria da qualidade da educação básica pública brasileira. $\mathrm{O}$ programa concede bolsa de iniciação à docência a alunos de cursos de licenciaturas que exerçam atividades pedagógicas em escolas públicas de educação básica, bem como aos professores responsáveis pela coordenação e supervisão dessas atividades.

O subprojeto do PIBID de Licenciatura em Inglês, da Faculdade de Letras da Universidade Federal do Rio de Janeiro (UFRJ), onde foram gerados os dados para essa pesquisa, intitula-se $A$ promoção do letramento crítico no ensino de inglês (TILIO, 2012). Esse subprojeto tem como objetivo contribuir para a formação inicial de novos professores de Inglês para a Educação Básica, aptos a entenderem a função da língua inglesa no mundo contemporâneo e transporem essa relevância para a sua prática pedagógica. Esse projeto assume como pressuposto básico que a função do ensino de inglês na educação básica é inserir o aluno no mundo globalizado, tornando-o agente crítico na sociedade em que atua. De acordo com os Parâmetros Curriculares Nacionais de Língua Estrangeira - PCN (1998), o projeto também entende que ensinar uma língua estrangeira significa orientar e sensibilizar o aluno em relação ao mundo multilíngue e 
multicultural em que vive, e que conhecer os discursos em uma língua estrangeira, mais especificamente o inglês, permite um maior acesso aos mais diferentes tipos de conhecimento, portanto maior inclusão social no mundo globalizado.

Esse projeto ocorre em uma escola da rede pública do Estado do Rio de Janeiro, localizada no bairro do Leblon, Rio de Janeiro e conta com um professor coordenador da Faculdade de Letras da UFRJ, cinco bolsistas licenciandos do Curso de Letras Português/Inglês e uma professora da escola que tem o papel de supervisora no projeto PIBID. Os bolsistas atuam em atividades desenvolvidas na escola, produção de material didático e reuniões pedagógicas semanais com o professor coordenador. Nas reuniões pedagógicas, os licenciandos discutem com o coordenador os planos de aula, dificuldades encontradas, projetos futuros, além de debaterem temas teóricos ligados ao ensino de língua inglesa.

As atividades desenvolvidas na escola ocorrem no contraturno do horário escolar dos alunos, duas vezes por semana, com duração de uma hora e meia. Essas atividades possuem uma abordagem sociointeracionista e objetivam principalmente desenvolver a habilidade oral dos alunos na língua inglesa já que, segundo a professora-supervisora da escola, essa habilidade não é priorizada nas aulas regulares do currículo escolar. Essas aulas do PIBID, chamadas de oficinas para que não haja confusão com as aulas regulares da grade curricular, são divulgadas aos alunos pela professora supervisora de inglês da escola. Ela visita todas as turmas da escola fazendo a divulgação e inscrição dos alunos. Assim, os alunos que se interessam podem se inscrever para a turma do semestre seguinte, já que o projeto se reinicia a cada seis meses. Muitos alunos se inscrevem, mas ao iniciarem as oficinas, nem todos os inscritos inicialmente ingressam no projeto e ao longo do semestre grande parte dos alunos deixa de frequentar as aulas.

\subsection{Os PARTICIPANTES ESTUDADOS}

Os participantes da pesquisa foram dois alunos graduandos de Letras Português-Inglês que conduziam as oficinas do período da manhã, acompanhados durante os meses de geração de dados. Ambos, 
além de serem integrantes do subprojeto Letras-inglês/UFRJ do PIBID/ CAPES, também estavam envolvidos em outros projetos e atividades extracurriculares da Faculdade de Letras, assim como também já trabalhavam como professores de inglês em cursos de idiomas particulares livres.

O professor coordenador do projeto e os alunos das oficinas também fazem parte dessa análise como participantes já que eles interagem com os professores em formação no processo da construção da autonomia. O número desses alunos presentes variava bastante nas oficinas, oscilando entre seis e 16. Esse número de seis alunos era formado por um grupo que sempre estava presente em todas as oficinas. Já os outros dez alternavam a presença em sala ao longo do semestre.

Para este trabalho foram atribuídos nomes fictícios para os participantes - professores em formação inicial: MARCELA e VITOR; e professor coordenador: RICARDO. Em função de serem vários alunos participantes, estes somente são citados quando os mesmos aparecerem nos dados.

\subsection{A GERAÇ̃̃o DOS DADOS}

A geração dos dados na escola ocorreu durante 14 oficinas nos meses de outubro e novembro de 2013. As oficinas duravam 1 hora e meia, iniciando às $10 \mathrm{~h} 30$ e terminando ao meio-dia. Os dois professores revezavam os dias da semana de acordo com as suas disponibilidades.

Para a geração dos dados foram utilizados: um diário de pesquisa em que as principais impressões acerca das atividades desenvolvidas durante as oficinas eram registradas pela pesquisadora (uma das autoras deste artigo), transcrições das gravações em áudio e vídeo de 14 dessas oficinas, além da gravação em áudio e vídeo de três reuniões pedagógicas.

A próxima seção será ilustrada com alguns dados gerados ao longo dessa pesquisa de forma a demonstrarmos a nossa compreensão acerca do desenvolvimento da autonomia sociocultural dos licenciandos no projeto PIBID. 


\section{A ANÁlise E A DISCUSSÃo DOS DAdOS}

Para efeitos deste artigo, limitamos o escopo em duas grandes categorias que chamaram a atenção no desenrolar desta pesquisa. Uma primeira em que observamos foi a interação entre licenciandos e $o$ coordenador PIBID durante as reuniões pedagógicas e outra categoria foi a interação entre licenciandos e seus alunos, durante as oficinas de inglês.

\subsection{A INTERAÇÃO ENTRE LICENCIANDOS E COORDENADOR DO PIBID}

A observação de uma primeira reunião pedagógica já permitiu constatar uma relação horizontal existente entre o coordenador do projeto e os licenciandos. Ou seja, apesar de RICARDO se encontrar em uma posição hierárquica superior a de seus alunos, essa relação vertical não parecia existir de fato nas interações entre eles, de tal forma que as reuniões pedagógicas eram fundamentadas por trocas de experiências. Os licenciandos atualizavam o coordenador sobre os conteúdos trabalhados e atividades realizadas em aula e também sobre como tinham transcorrido as últimas aulas. Nessa troca de informações todos os presentes opinavam e colaboravam para que o trabalho deixasse de ser individual, para se tornar um trabalho coletivo.

No EXCERTO 1, a seguir, podemos perceber que todos os integrantes do projeto trabalham trocando experiências. MARCELA descreve as atividades de sua última aula e do projeto final que propôs aos alunos da turma e os outros professores interferem fazendo perguntas ou observações sobre a aula. Verifica-se também a tomada de turno por parte de MARCELA que é bastante longa, o que parece demonstrar o espaço que é aberto para ela durante as reuniões. Percebe-se que a fala do coordenador não é dominante sobre a dos professores licenciandos, pelo menos em termos de quantidade de tomada de turnos por cada um deles:

EXCERTO 1 - REUNião PEDAGÓGICA DO DiA 30 DE OUTUBRO DE 2013.

RICARDO: Isso foi sua aula de ontem?

MARCELA: É. A gente falou do final de semana, ai eu mostrei um vídeo [...]. Ai depois a gente falou do projeto, foi rapidamente. Pensamos assim, a gente vai fazer uma votação lá no grupo do nome. Deixei pra 
eles resolverem. Deixei até em branco aqui o nome do projeto. [...] dei algumas ideias. [...] Que eles já escreveram bastante coisas sobre isso aqui.

RICARDO: Que é...

RICARDO: Lendo junto com MARCELA: general information.

Sueli: Legal.

MARCELA: Eles estão empolgadinhos.

RICARDO: Uhum.

Tadeu: Você trabalhou simple past que eu vi ali.

MARCELA: Sim, tudo que eu mostrei.

Tadeu: É que tinha um worksheet, no Word

MARCELA: Era aquilo.

Tadeu: Ah tá. Era do information gap.

MARCELA: Information gap e aquela outra atividade. Então você copia tudo.

Tadeu: Belezão.

VITOR: Eu até vou te passar se não eu vou esquecer o slide do... halloween...se quiser usar depois.

Tadeu: Mas é stories porque é mais de um grupo, é isso?

MARCELA: Cada um vai contar a sua história. Eles até falaram assim. A professora deve tá curiosa pra saber a nossa história. Ela nem imagina!

É possível perceber o trabalho colaborativo existente entre os professores em formação e o coordenador, o que é essencial para a formação do sujeito coletivo de aprendizagem. Todos se interessam pela aula de MARCELA e querem compreender cada etapa da mesma. Parece que esse interesse coletivo, além de valorizar o trabalho do colega, favorece a construção de conhecimento em conjunto. Essa troca de ideias entre os participantes do projeto foi tão intensa que chamou a atenção, conforme dados do diário da pesquisadora.

ExCERTo 2: Dí́RIo DE PESQUisA - 30 DE OUTUBRo DE 2014.

RICARDO não determina o que cada um deve fazer. Ele deixa os bolsistas "livres" para montarem suas aulas. Também os deixa a frente das discussões. 
Segundo Engenstron, esse sujeito coletivo só é possível pela "associação das atividades e capacidades intelectuais e práticas de aprendizes e professores" (ENGENSTRON, 1984, p.144). Para reforçar essa importância do trabalho coletivo retomamos as palavras de Liberali (2009) ao afirmar que "em colaboração os sujeitos vão além de suas possibilidades imediatas" (LIBERALI, 2009, p. 248). Essa questão do trabalho coletivo está em concordância com o conceito de zona de desenvolvimento imediato de Vigotski (2010). Segundo ele:

Através da imitação na atividade coletiva, orientada pelos adultos a criança está em condições de fazer bem mais, e fazer compreendendo com autonomia. A divergência entre os níveis de solução de tarefas - acessíveis sob orientação - com o auxílio de adultos e na atividade independente determina a zona de desenvolvimento imediato (LIBERALI, 2010, p. 480).

Apesar das palavras de Vigotski (2010) serem dirigidas à aprendizagem de crianças, acreditamos que a noção de zona de desenvolvimento imediato auxilia também adolescentes e adultos a buscarem coletivamente soluções para o desempenho de suas tarefas. Ainda nesse sentido, Liberali (2009) acrescenta que a zona de desenvolvimento imediato permite prever o estado dinâmico do desenvolvimento do aprendiz, já que leva em consideração tanto o já atingido, como também tudo que se encontra em processo de amadurecimento.

Complementarmente, observamos de forma clara que o coordenador, sempre que possível, dava espaço a seus professores para interferirem nos objetivos e metas já predefinidos para o projeto. Em uma das reuniões pedagógicas, o orientador pede aos professores para compartilharem suas ideias e planos para o PIBID e sugere a leitura de um texto para que sejam inspirados e possam traçar novos caminhos para o projeto. Vejamos a sua fala nos excertos a seguir.

ExCERTo 3 - REUnião PEDAGÓGica do diA 30 de outubro de 2013.

RICARDO: Bom, mais algum comentário sobre planos, dúvidas, alguma coisa? 
EXCERTo 4 - Reunião PEDAGÓGica do dia 30 de OUTUBRo de 2013.

RICARDO: Discutir esse projeto lá da UFPR é pra gente pegar emprestado algumas ideias, né, para as nossas práticas. Mais do que isso, pensar criticamente o que enfim, coisas positivas, coisas não tão positivas. Então. Vamos lá.

Esses dois últimos excertos demonstram que o orientador não só compartilha com os professores em formação a oportunidade de definirem objetivos e metas para o projeto PIBID-inglês, mas também oferece a eles a chance de refletirem de forma crítica o próprio trabalho. Assim, esses professores em formação inicial estão sendo estimulados a serem "críticos, dispostos a vozear suas perspectivas, angústias e desejos de transformação da sociedade" (NICOLAIDES; TILIO, 2011, p. 194).

Os dados gerados sugerem que os professores conseguem aproveitar essa oportunidade de se posicionarem como sujeitos ativos participantes do processo de construção do conhecimento e engajam-se contribuindo com sugestões e propostas para o projeto. No EXCERTO 5 , a seguir, durante uma reunião pedagógica, VITOR compartilha com seus colegas e com o professor coordenador uma proposta sua para o próximo semestre. $O$ professor coordenador além de aceitar a nova proposta, pede a opinião do licenciando sobre como articular essa nova ideia com as já existentes.

ExCERTo 5 - Reunião PedAGÓGICA do dia 4 de DEZEMBRo de 2013.

VITOR: Eu vi no youtube que tem um colégio americano, que eles recebem crianças com problemas de fala, troca letras e etc. Ai o professor organizou um projeto, um coral, pra trabalhar pronúncia e é uma coisa que faltou muito esse semestre na nossa turma, principalmente porque era muito difícil, porque a gente não teve uma constância de alunos presentes. Era muito quebrado. Não sei a MARCELA, mas eu fiquei muito a desejar nessa parte da pronúncia. Acho que faltou, achei um projeto legal, não toma muito tempo. Pode ser um projeto sidebyside. Tipo 11:40, então vamos gente qual música a gente vai treinar hoje? 
RICARDO: Entendi. Então você acha que dá pra gente ter um projetão principal, que pode ser um projeto de 1 mês ou 1 bimestre, mas sempre reservando um pouco de cada aula pra esse sub-projeto. VITOR: Meu medo era esse. Aqui a gente teve muita gente que botou a carinha não mais feliz para o projeto. Então não sei, não gostei porque faltei muito porque era um projeto. Então pensei em fazer tipo isso, essa parte da pronúncia com música como lúdico, por fora, um atrativo e não como um projeto que vai dar nota. (Neste trecho Vinícius se refere ao questionário de avaliação que pediram aos alunos para responderem ao final do semestre e cita exemplo de resposta de aluno).

Na verdade, VITOR está propondo uma nova ideia para o próximo semestre como uma alternativa para um problema (dificuldade de trabalhar a pronúncia dos alunos) enfrentado no semestre corrente. Esse problema só foi identificado em função da prática dialógica existente entre alunos e professores (através do dia a dia de sala de aula e de um questionário aplicado pelos licenciandos aos alunos) e a solução proposta surge também através de um diálogo entre licenciandos e professor coordenador. Assim, percebemos a importância do diálogo na construção de conhecimento, como afirma Freire que "não há inteligibilidade que não seja comunicação e intercomunicação e que não se funde na dialogicidade. O pensar certo por isso é dialógico" (FREIRE, 1996, p. 38).

No último dia de aula do semestre, os dois professores em formação ao conversarem no final da aula sobre o trabalho final da biografia que os alunos apresentaram, comentam sobre a possibilidade e vontade de realizarem uma pesquisa sobre esse trabalho da turma. Vejamos a fala de MARCELA:

ExCerto 6 - Aula Do dia 26 De nOVEMBro de 2013.

MARCELA: Isso dá uma ótima pesquisa. Isso que a gente tem que falar com o RICARDO. Tem que pensar num foco todo semestre. Ter um projeto final e as aulas serem direcionadas.

VITOR: É muito ruim trabalhar sem...

MARCELA: Porque tem que ter um foco. Os alunos se sentiram motivados, eu acho. 
Nessa conversa, percebemos que MARCELA e VITOR se sentem bem à vontade para propor novas ideias para o PIBID com base em uma avaliação de resultados observados. E de fato, foi o que aconteceu na reunião pedagógica seguinte. Eles lançaram essa proposta ao orientador, de trabalharem com os alunos baseados em projetos, pois segundo eles, desta forma os alunos se sentem mais motivados e engajados nas aulas.

Da mesma forma, os licenciandos foram responsáveis por mudanças ocorridas no planejamento pedagógico do semestre, assim como na forma de avaliação. A proposta inicial do semestre era a de trabalhar com o material didático usado na disciplina de inglês curricular da escola, porém de forma complementar, enfatizando principalmente o uso da oralidade na língua inglesa que é quase inexistente nas aulas da grade curricular, segundo informações da professora de inglês da escola. Contudo, ao longo das aulas, os professores perceberam que essa proposta inicial não estava evoluindo muito bem. Isso porque os alunos se esqueciam de levar o livro para as aulas, prejudicando o planejamento da aula, assim como também perceberam que os alunos não estavam se envolvendo tanto nas aulas. Todas essas dificuldades eram compartilhadas nas reuniões pedagógicas e discutidas por todo o grupo de professores em conjunto com o coordenador que sempre os deixou livres para proporem novas ideias. Com isso, novos insights surgiram por parte dos professores e a nova proposta sugerida pela MARCELA foi a adotada para o restante do semestre com a oficina do turno da manhã.

Os dados gerados ao longo das reuniões pedagógicas mostram que os professores em formação eram os responsáveis pelo conteúdo a ser trabalhado em sala de aula. Nas reuniões pedagógicas eles compartilhavam com o coordenador e com o grupo de professores o que haviam feito nas últimas aulas e os planos para as próximas. Sempre que julgava necessário o professor coordenador questionava e complementava as sugestões dos professores para orientá-los da melhor forma possível na definição dos planos de aula. No EXCERTO 7, a seguir, MARCELA, durante a reunião pedagógica, compartilha com o grupo a sua proposta para as aulas até o final do semestre e RICARDO interfere em vários momentos fazendo questionamentos. Esses questionamentos 
parecem ajudá-la a refletir e direcionar da melhor forma possível o projeto final.

EXCERTo 7 - REUNião PEDAGÓGICA do diA 30 DE OUtUBRo de 2013.

RICARDO: E a ideia depois que você coletar todas essas histórias é? MARCELA: Não sei, alguma coisa.

RICARDO:Não pensou ainda no formato final?

MARCELA: Não, seria um livro mesmo, um diário com as histórias dos alunos. O que a gente vai fazer com isso depois, quem sabe!

RICARDO: Fazer um livro, assim você pensa em botar tudo junto, encadernar, fazer uma coisa assim?

MARCELA: Sim.

RICARDO: A sua previsão é disso durar quantas aulas?

MARCELA: Até o final.

RICARDO: Mas você já parou pra contar quantas aulas são?

MARCELA: Ainda não fiz isso.

RICARDO: Porque o final do ano de repente vai ser mais rápido do que você imagina.

MARCELA: Era isso que eu queria ver com você. Eu queria fazer um cronograma, mas eu queria ver com você quando seria o último dia.

Além de participar ativamente da determinação de conteúdo para as aulas, os professores em formação inicial também definem as formas de avaliação para os alunos. Em virtude do projeto final proposto para o final do semestre, MARCELA sugere que não adotem a avaliação escrita e oral nos moldes já utilizados nos outros semestres do PIBID, mas utilizem a apresentação final dos diários como avaliação dos alunos. Vejamos o excerto a seguir.

ExCERTo 8 - Reunião PedAGógica do dia 30 de outubro de 2013.

MARCELA: Talvez já que o calendário tá meio apertado, porque não a avaliação ser esse projeto?

RICARDO: Ah, com certeza, com certeza. Porque a coisa meio que perdeu o sentido. 
Esses dados parecem indicar que a relação entre coordenador e licenciandos está baseada em um trabalho compartilhado para construir conhecimento entrando assim em consonância com Freire (1996, p. 22) ao afirmar que "ensinar não é transferir conhecimento, mas criar possibilidades para a sua produção ou a sua construção". É possível perceber que o professor coordenador tenta criar possibilidades para que os professores em formação criem seu próprio conhecimento para definirem conteúdo e formas de avaliação a serem adotadas no PIBID. Freire ainda acrescenta que "o educador democrático não pode negarse do dever de, na sua prática docente, reforçar a capacidade crítica do educando, sua curiosidade, sua insubmissão" (FREIRE, 1996, p. 26) e que "nas condições de verdadeira aprendizagem os educandos vão se transformando em reais sujeitos da construção e da reconstrução do saber ensinado, ao lado do educador, igualmente sujeito do processo" (FREIRE, 1996, p. 26).

\subsection{A INTERAÇÃO ENTRE LICENCIANDOS E ALUNOS}

Da mesma forma que a relação entre coordenador e licenciados era equilibrada, a relação entre os licenciandos e alunos do PIBID também era muito horizontal. Percebemos uma aproximação entre esses participantes de pesquisa e compreendemos que a sala de aula também funcionava como um espaço de compartilhamento de ideias. É possível observar esse tipo de relação no EXCERTo 9 a seguir, no qual, após fazer a proposta do projeto final para a turma, a professora quer ouvir o que os alunos têm para falar. MARCELA não quer impor um trabalho para a turma, os dados indicam que ela deseja que a responsabilidade do trabalho seja compartilhada com os alunos. Em outras palavras, a professora parece estar dando a eles a oportunidade de se responsabilizarem pela sua própria aprendizagem, o que torna esse processo mais significativo e propício ao desenvolvimento da autonomia. Esse cenário vai ao encontro da definição de Vieira (2007) do que seria uma pedagogia para autonomia. Segundo essa autora, deve existir uma proximidade entre alunos e o processo e conteúdo de aprendizagem, assim como o contexto escolar deve favorecer as condições para que o aluno seja capaz de gerenciar de forma crítica sua própria aprendizagem. Vejamos os dados a seguir: 
ExCERTo 9 - Aula do dia 22 de OUtUBro de 2013.

MARCELA: Ok. Então vou conversar com o Vi amanhã sobre isso. A gente vai pensar. Eu queria ver qual seria a reação de vocês. Pois não adianta nada eu propor alguma coisa e vocês, ah não quero.

EDUARDO: Né, Tainara?

TANIA: Né o quê?

MARCELA: Tão animados?

(...)

EDUARDO: O pior que é verdade.

TANIA: Tenho uma história que dá um livro

MARCELA: Vocês vão ver. Se a gente trabalhar legal.

CARLA: Vai dar um livro.

MARCELA: Vai dar um livro.

MARCELA: Então vou falar como Vi amanhã pra ver como a gente.

EDUARDO: Professora. Eu tenho tipo assim, umas coisas escritas em casa desde pequeno então eu poderia, traduzir.

MARCELA: Claro. Alguém desenha?

CARLA: Eu um pouco.

MARCELA: Isso pode fazer parte também, pode ser, gente criatividade. Não precisa só escrever. Pode adicionar um desenho, alguma, enfim. Vocês podem fazer o que vocês quiserem. A história é sua. [...] Vou falar como VITOR e a gente vai ver como vamos fazer isso direitinho e a gente traz respostas pra vocês. See you.

Pode-se observar que tanto no discurso da professora, como na própria tarefa em si por ela proposta, há uma vontade que seus alunos de fato construam a sua própria história - não só na forma que o trabalho venha a ser conduzido, mas no objetivo que é dar oportunidade aos alunos para socializarem suas histórias de vida.

Os dados a seguir reforçam a visão de sala de aula como espaço de compartilhamento de conhecimento, onde todos são igualmente responsáveis pelo processo de ensino-aprendizagem, o que está em sintonia com a afirmação de Vigotski (2010) sobre o processo educativo. Segundo esse autor, o processo educativo é "trilateralmente ativo" (VIGOTSKI, 2010, p. 73); é ativo o aluno, é ativo o mestre, é ativo o meio criado entre eles. 
Logo na primeira oficina, em 08 de outubro de 2013, foi registrado pela pesquisadora, em seu diário de pesquisa, o professor VITOR dizer a um aluno: "Confia no amigo, o amigo sabe." Como não foi possível ouvir o contexto que aquela frase havia sido dita, no final da aula foi pedido ao professor licenciando que fizesse um comentário sobre aquele momento. $\mathrm{O}$ professor relatou que uma aluna tinha uma dúvida e mesmo após consultar o colega, ela quis confirmar com o professor. $\mathrm{O}$ professor ainda acrescentou que infelizmente esse tipo de atitude acontece muito, ou seja, os colegas só confiam na resposta do professor. Vejamos os dados do diário de pesquisa

ExCerto 10: Dí́rio de pesquisa - 08 de outubro de 2014.

Perguntei sobre o momento "eu te falei". Vitor disse que aluno foi tirar uma dúvida (find/found) e quando ele confirmou, a outra aluna disse: “Eu te falei!'. Por isso ele disse a eles que eles devem confiar no amigo.

Em momento posterior, a professora MARCELA, por ser a semana do dia dos professores, preparou uma aula com a temática: professores e alunos. Nessa oficina ela lançou para a turma uma discussão sobre o papel dos professores e alunos e o que faz um bom professor e um bom aluno. O simples fato de a professora lançar essa discussão em sala de aula, já revela muito sobre as suas concepções no que diz respeito professores e alunos, já que se as suas concepções fossem tradicionais, esse espaço para discussão dificilmente iria existir. Também acreditamos que ela não queria simplesmente definir esses papéis, mas sim, que os alunos refletissem de uma forma mais crítica sobre o tema para fazerem uma relação com a realidade que os rodeia.

A leitura do EXCERTo 11 possibilita a percepção, como já mencionado, de que a professora estimula os alunos a compartilharem suas ideias e crenças, contudo, ela, mesmo sendo a professora, não expõe a sua opinião. Ou seja, fica evidente que a professora entende que o professor não é um detentor de conhecimento, mas sim um dos agentes do processo educativo que oferece meios para que alunos criem e recriem conhecimento. Retomando as palavras de Freire, entendemos que nas condições de verdadeira aprendizagem, os educandos vão se transformando "em reais sujeitos da construção e da reconstrução do 
saber ensinado, ao lado do educador, igualmente sujeito do processo" (1996, p. 26). Vejamos o excerto a seguir:

ExCERTo 11 - Aula Do dia 10 de OUtUbro de 2013.

MARCELA: Ok? So what's the importance of the teacher?Pra que que serve o professor? Pra nada?

ALUNOS: Pra ensinar.

Marcia: Pra fazer o aluno a pensar.

MARCELA: Sophilosophical.

JONAS: Marlene.

MARCIA: Marlene, a gente aprendeu isso no ano passado. Não, ela só falou isso. Que o professor não deve tá ali para ensinar, é pra fazer a gente a pensar.

Luiz: Fazer o aluno pensar.

RAFAELA: Passar conhecimento.

MARCELA: Passar conhecimento.

JORGE: Era o meu comentário, eu ia falar isso.

MARCIA: What else?

(...)

MARCIA: É aquele professor, a gente tava conversando sobre isso. Aquele professor que interage com você, ele não é só um professor. Ele tá ali pra ser teu amigo, pra te ajudar, essas coisas assim.

MARCELA: What else?

TANIA: Os professores do ano passado eram assim, diferentes dos daqui desse ano.

MARCELA: Nothing else? And what about the student?What's the importance of the student? What's the role of the student?

MARCIA: Eu acho que o estudante é meio que assim, você tá criando, praticamente, então ele vai ser meio que, vamo dizer, seu semelhante. O que você ensinar ele vai ser futuramente parecido com você, então é meio que sua cria, assim. Não sei explicar direito.

Complementarmente, os dados seguintes (ainda sobre a discussão do papel do professor, com base em uma imagem - anexo, imagem 1) parecem indicar que a professora instiga os alunos a compreenderem que o conhecimento também está nos alunos e que estes são essenciais 
no processo de ensino-aprendizagem. Também é possível perceber que os alunos sentem necessidade de serem valorizados pelos professores e que dessa forma a construção e transformação de conhecimento seriam muito mais produtivas. Como afirma Vigotski, "qualquer situação de aprendizado, com o qual a criança se defronta na escola, tem sempre uma história prévia" (2007, p. 94), visto que essa criança (aprendiz) constrói uma série de conhecimentos ao interagir com o mundo que a cerca.

ExCERTo 12 - Aula Do dia 10 DE OUtubro De 2013

Jonas: Professor amigo

MARCELA: Professor amigo, ensinar como fazer e eles estão se equilibrando numa mesma corda. Ou seja, como a Ruana disse todo mundo no mesmo barco. Então como é que vocês enxergam isso?

RUANA: Que o professor não tá se botando acima do aluno

MARCELA: O professor tá no mesmo nível [...] então qual é o papel do professor?

JORGE: Ajudar os alunos

ALUNO (aluno não identificado): Troca de saberes.

MARCELA: Troca de saberes. Very good. What else? Alguém falou aqui antes em passar conhecimento, como se fosse transmitir, igual aquelas primeiras figuras (anexo imagens 2 e 3). Eu abro a cabeça de vocês. Mas aí isso implica que o professor detém o conhecimento, eu sei de tudo, você não sabe de nada, vou passar tudo. É assim que funciona?

ALUNOS: Não.

MARCELA: Como é que funciona? Como deveria funcionar?

DANIELA: Eu acho que o professor deveria explicar e deixar os alunos falarem.

MARCELA: Então a participação dos alunos...

DANIELA: Participação dos alunos

MARCELA: Como agora, right? A participação dos alunos. (risadas)

A fala da MARCELA, neste último excerto, parece demonstrar que ela tem consciência da sua proposta de ensino e que essa proposta 
está voltada a permitir que alunos participem da aula em conjunto com o professor para a construção de conhecimento. Da mesma forma, a sua proposta para o projeto final das biografias favorece esse engajamento entre alunos e professores na construção de significado e conhecimento. Vejamos o excerto a seguir.

ExCERTo 13 - Aula do dia 22 de OUtubro de 2013.

MARCELA: É uma ideia. Mas o que que vocês acham disso? Mas eu quero que a gente também entre de cabeça. Não é pra não, melhor não fazer. Fazer direito. Que que vocês acham? Eu acho que vocês vão desenvolver mais. Que vocês vão ter o que fazer fora daqui também. [...] Eu queria ver qual seria a reação de vocês. Pois não adianta nada eu propor alguma coisa e vocês, ah não quero.

Este último excerto parece dialogar com Lantolf e Pavlenko (2001, p. 146) que expressam a necessidade de significado para a agência do aprendiz.

A agência humana é muito mais do que performance, ou fazer; está intimamente atrelado a significado. Ou seja, coisas e eventos têm importância para as pessoas - suas ações têm significado e interpretações. É a agência que une motivação [...] à ação e define uma variedade de caminhos a serem seguidos pelos alunos.

Desta forma, parece que a professora ao propor esse projeto das biografias, gostaria que os alunos se sentissem motivados e, consequentemente, se envolvessem para serem agentes do próprio aprendizado.

\section{CONSIDERAÇÕES FINAIS}

Neste artigo procuramos mostrar alguns dados que revelam a relevância da participação ativa de aprendizes na tomada de decisões no que se refere à aprendizagem em dois momentos. $\mathrm{O}$ primeiro diz respeito aos professores de línguas em formação e o segundo aos alunos desses professores que buscam a aprendizagem de uma língua adicional. Nossos dados levam a crer que em ambos os casos a interação entre 
os participantes e o espírito de coletividade propiciou uma autonomia sociocultural por parte dos aprendizes, como aqui advogamos. Em um contexto de pesquisa em que os professores em formação ora são aprendizes (ao interagirem com o coordenador do projeto PIBID), ora são professores, parece que a oportunidade criada pelo coordenador de certa forma faz com que esses futuros professores também acreditem na importância da agência de seus alunos no processo de ensino e aprendizagem.

Lançando mão mais uma vez dos pressupostos da TSC, invocamos Lantolf e Pavlenko que ao versarem sobre agência afirmam:

As pessoas são agentes encarregados de sua própria aprendizagem, e muito frequentemente decidem aprender uma segunda língua 'até um certo ponto", o que os permite tornarem-se proficientes, até mesmo fluente, mas sem as consequências de perder a velha e adotar novas formas de ser no mundo. (LANTOLF; PAVLENKO, 2001, p. 162).

Assim, ao analisarmos dois momentos diferentes de interação em que esses futuros professores atuam tanto como quem aprende e como quem ensina, observamos um bom espaço para que tenham agência sobre sua própria aprendizagem. Obviamente que como e quanto cada um vai se envolver ou encarregar-se de sua própria aprendizagem vai depender de uma rede complexa de fatores, difíceis de serem todos abordados. Fatores como traços de personalidade, interesses e identificação com a língua a ser aprendida, estilos de aprendizagem são apenas alguns dos fatores que podem colaborar ou dificultar para que o aluno se encarregue ou não por sua própria aprendizagem. Todavia, mais relevante do que isso, parece ser o ambiente propício que encontramos neste contexto PIBID para o desenvolvimento de um espírito de coletividade, que entra em consonância com o que Oxford (2003) trata como autonomia sociocultural. Tanto nas reuniões pedagógicas do coordenador do projeto com seus alunos, como quando esses alunos exercem o papel de professor, há um explícito esforço para que as práticas pedagógicas sejam decididas coletivamente entre professor e alunos. Mesmo quando os alunos desses futuros professores, por talvez ainda não estarem acostumados com uma cultura de sala de aula em que 
o professor não é o centro, mas em que o foco deva ser a aprendizagem do grupo, VITOR faz seus alunos refletirem ao dizer "Confia no amigo, o amigo sabe."(EXCERTo 10)

Não podemos fazer uma relação direta afirmando que o fato do professor coordenador, durante as reuniões do PIBID, criar esse ambiente de colaboração entre ele e seus alunos pode ter influenciado também no desempenho desses alunos ao atuarem como professores. Mas podemos dizer que os dados nos levam a crer que os professores se sentem à vontade para fazer suas considerações e interferências ao longo do projeto, o que certamente os faz refletir que o papel do aluno não é o de simplesmente sujeitar-se a aquilo que o sistema lhe impõe, mas como Pennycook afirma ao tornarem-se autônomos tornam-se "autores do próprio mundo" (PENNYCOOK, 1997, p. 45).

Nesse sentido, não podemos deixar de retomar aqui o projeto sobre histórias de vida proposta por MARCELA e seus colegas que nos serve como exemplo de uma tarefa que em dois sentidos são importantes para o estímulo ao desenvolvimento da autonomia sociocultural de seus alunos - na sua essência ao propor aos alunos que compartilhem suas histórias de vida, o que acaba por dar oportunidade para que se tornem autores de seu próprio mundo, pois narram suas experiências de vida sob sua perspectiva; e também na forma que a tarefa é proposta, em que professores e alunos negociam em conjunto a melhor forma em que o projeto deve ser encaminhado.

Sendo assim, vale ressaltar que cabe a nós, professores e pesquisadores, a tarefa de continuar pesquisando e estudando caminhos que valorizem e estimulem a construção de autonomia sociocultural de alunos e professores, não só dentro dos muros escolares, mas também fora deles.

Por fim, citamos Rego (1994) que aponta a necessidade de "uma escola em que as pessoas possam dialogar, duvidar, discutir, questionar e compartilhar saberes. Onde há espaço para transformações, para as diferenças, para o erro, para as contradições, para a colaboração mútua e para a criatividade" (p.118) e Vieira (2007, p. 51) que sonha com uma nova realidade.

A esperança pedagógica e a autonomia profissional andam de mãos dadas na luta por uma educação melhor: uma educação que é eman- 
cipatória para professores e alunos e que, em última análise, contribui para a transformação da sociedade em geral. Se isto soar a utopia, então soa bem. Apenas os ideais podem fazer com que a realidade avance, e não sermos capazes de cumpri-los plenamente é justamente mais uma razão para continuarmos a tentar. Desta perspectiva, lidar com a complexidade e com a incerteza é essencial a uma aprendizagem profissional "re[ide]alista" ao longo da vida.

\title{
Promoting SOCIOCULTURAL AUTONOMY IN PRE-SERVICE TEACHER EDUCATION OF ENGLISH IN THE PIBID/CAPES CONTEXT
}

\begin{abstract}
In a research context of the subproject Letters- English/UFRJ PIBID/CAPES it was possible to observe a balance concerning decision making by students. Instead of students guided by tasks only defined by their coordinator, they became more responsible for their work. This paper aims to understand the promotion of sociocultural autonomy (OXFORD, 2013) among undergraduate students involved in the project. We bring up some examples on how the conduction of this PIBID Project was carried away along pedagogical meetings and how this balance of decision making reflects in the classroom when these undergraduate students act then as teachers.
\end{abstract}

KEYwORDS: sociocultural autonomy, pre-service teacher education, language teaching.

PROMOCiÓN DE LA AUTONOMÍA SOCIOCULTURAL DE PROFESORES DE INGLÉS EN FORMACIÓN INICIAL EN EL CONTEXTO PIBID/CAPES

\section{RESUMEN}

A partir de la observación y del análisis de un contexto de investigación del sub-proyecto Letras-Inglés/UFRJ del PIBID/CAPES se verificó que los licenciados, en lugar de guiarse apenas por las tareas definidas por el coordinador, se responsabilizaban por el trabajo, ocasionando un equilibrio en lo que se refiere a la tomada de decisiones entre esos participantes del proyecto. De esa forma, este trabajo tiene el objetivo de comprender la promoción de la autonomía sociocultural (OXFORD, 2003), por parte de los licenciados envueltos en el proyecto, destacando algunos ejemplos de cómo la conducción 
de ese Proyecto PIBID aconteció a lo largo de las reuniones pedagógicas y como ese equilibrio en la tomada de decisiones se reflete, en la sala de clase, cuando esos licenciados pasan a actuar como profesores,

PALABRAS-CLAVE: autonomía sociocultural, formación inicial de profesores, enseñanza de lenguas.

\section{NotA}

1 Optou-se por adotar o termo "ensino-aprendizagem" já que as autoras partem do pressuposto que ensino e aprendizagem são processo imbricados e que dificilmente ocorrem um sem o outro.

\section{REFERÊNCIAS}

BENSON, P. The philosophy and politics of learner autonomy. In: BENSON, P; VOLLER, P. Autonomy and independence in language learning. London: Longman, 1997.

ENGENSTRON, Y.; HAKKARAINEN, P.; HEDEGAARD, M. On the methodological basis of research in teaching and learning. In: HEDEGAARD, M; HAKKARAINEN, P; ENGENSTRON, Y (Org.). Learning and teaching on a scientific basis. Aarhus, Denmark: Aarhus University, 1984. p. 119-189.

FREIRE, P (1996). Pedagogia da autonomia: saberes necessários à prática educativa. São Paulo: Paz e Terra, 2008.

HUNTER, J.; COOKE, D. Through autonomy to agency: Giving power to language learners. In: Prospect, v. 22, n. 2 2007. Disponível em: <http://www. ameprc.mq.edu.au/_data/assets/pdf_file/0019/67060/Prospect_22,_2_5 Hunter.pdf $>$.

LANTOLF, J. Introducing sociocultural theory. In: LANTOLF, J. Sociocultural Theory and Second Language Learning. Hong Kong: Oxford University Press, 2000. p.1-26.

LANTOLF, J; PAVLENKO, A. Second language activity theory: understanding second language learners as people. In: BREEN, M. P. Learner Contributions to Language Learning: New Directions in Research. New York: Longman, 2001. p. 141-158. 
LIBERARI, F. C. Por um sujeito livre que não teme: faz escolhas. In: SCHETTINI et al. (Org.). Vygotsky: uma revisita no início do século XXI. São Paulo: Andross, 2009. p. 233-254.

MARTINEZ, H. The subjective theories of student teachers Implications for teacher education and research on learner autonomy. In: LAMB, T.; HAYO, T. Learner and Teacher Autonomy Concepts, realities, and responses. Amsterdam: John Benjamins Publishing Company, 2008.

NICOLAIDES, C. A busca da aprendizagem autônoma de língua estrangeira no contexto acadêmico. Tese (Doutorado em Letras) - Instituto de Letras, Universidade Federal do Rio Grande do Sul, Porto Alegre, 2003.

NICOLAIDES, C. TILIO, R. O material didático na promoção da aprendizagem autônoma de línguas por meio do letramento crítico. In: SZUNDY, P. T, C.; ARAÚJO, J. C.; NICOLAIDES, C. S. SILVA, K. A. Línguistica Aplicada e Sociedade: Ensino e Aprendizagem de línguas no contexto brasileiro. Campinas: Pontes, 2011. p. 175-196.

NORTON, B. Identity and language learning: gender, ethnicity and educational. Change. Harlow: Longman, 2000.

OXFORD, R. L. Toward a more systematic model of L2 learner autonomy. In: PALFREYMAN, D.; SMITH, R. (Ed.). Learner autonomy across cultures: language education perspectives. New York, Palgrave Macmillan, 2003. p. 75-91.

. L2 Learner autonomy in the crucible. In: BARCELOS, A. M. F. (Org.). Linguística Aplicada: reflexões sobre ensino e aprendizagem de língua materna e língua estrangeira. Campinas, SP: Pontes Editores, 2011.

PAIVA, V L. M; BRAGA, J. C. F. The complex nature of autonomy. D.E.L.T.A., v. 24, n. especial, p. 441-468, 2008.

REGO, T. C. Vygotsky: uma perspectiva histórico-cultural da educação. Petrópolis, RJ: Vozes, 2011.

TILIO, R. C. A promoção do letramento crítico no ensino de inglês. Subprojeto Letras-Inglês do PIBID/CAPES, 2012.

PENNYCOOK, A. Cultural alternatives and autonomy. In: BENSON, P.; VOLLER, P. (Ed.). Autonomy and independence in language learning. Essex: Addison Wesley Longman, 1997.

ROUSSEAU, J. J. Emílio ou da educação. 3. ed. Tradução Ricardo Leal Ferreira. São Paulo: Martins Fontes, 2004.

VIEIRA, F. Addressing constraints on autonomy in school contexts: lessons from working with teachers. In: PALFREYMAN, D.; SMITH, R.C.(Ed.). 
Learner autonomy across cultures: language education perspectives. Basingstoke: Palgrave Macmillan, 2007. p. 220-237.

VIGOTSKI, L. S. Psicologia Pedagógica. São Paulo: Martins Fontes, 2010. . A formação social da mente. São Paulo: Martins Fontes, 2007. . Pensamento e Linguagem. São Paulo: Martins Fontes, 2008.

Submetido em 31 de outubro de 2015.

Aceito em 25 de maio de 2016.

Publicado em 23 de novembro de 2016.

7. ANEXo

\section{IMAGEM 1}

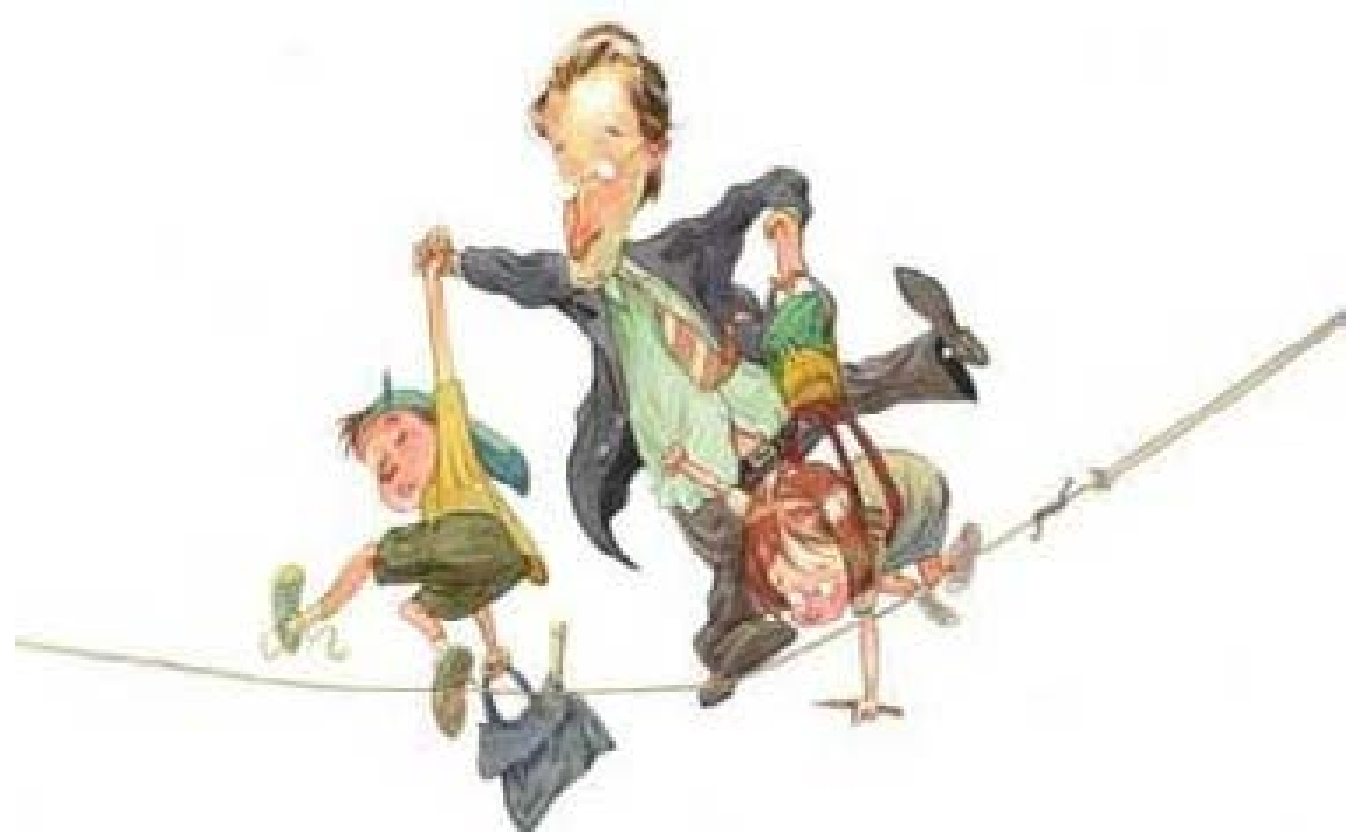


IMAGEM 2

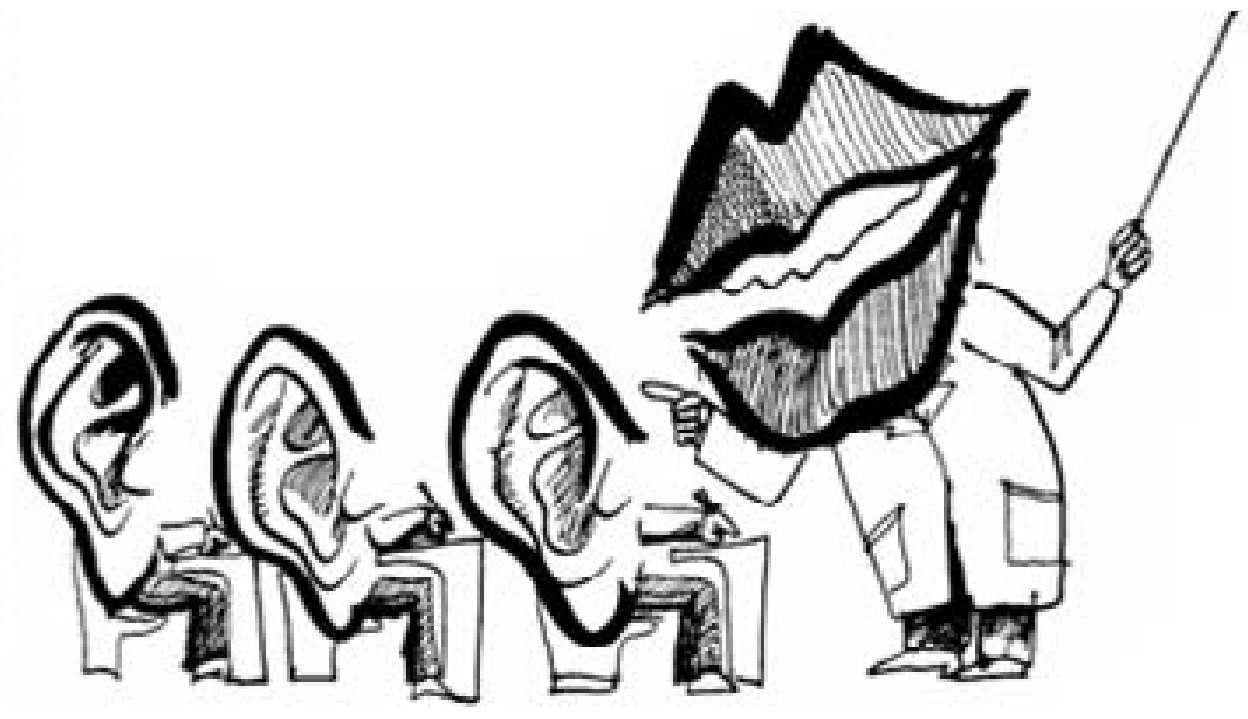

IMAGEM 3

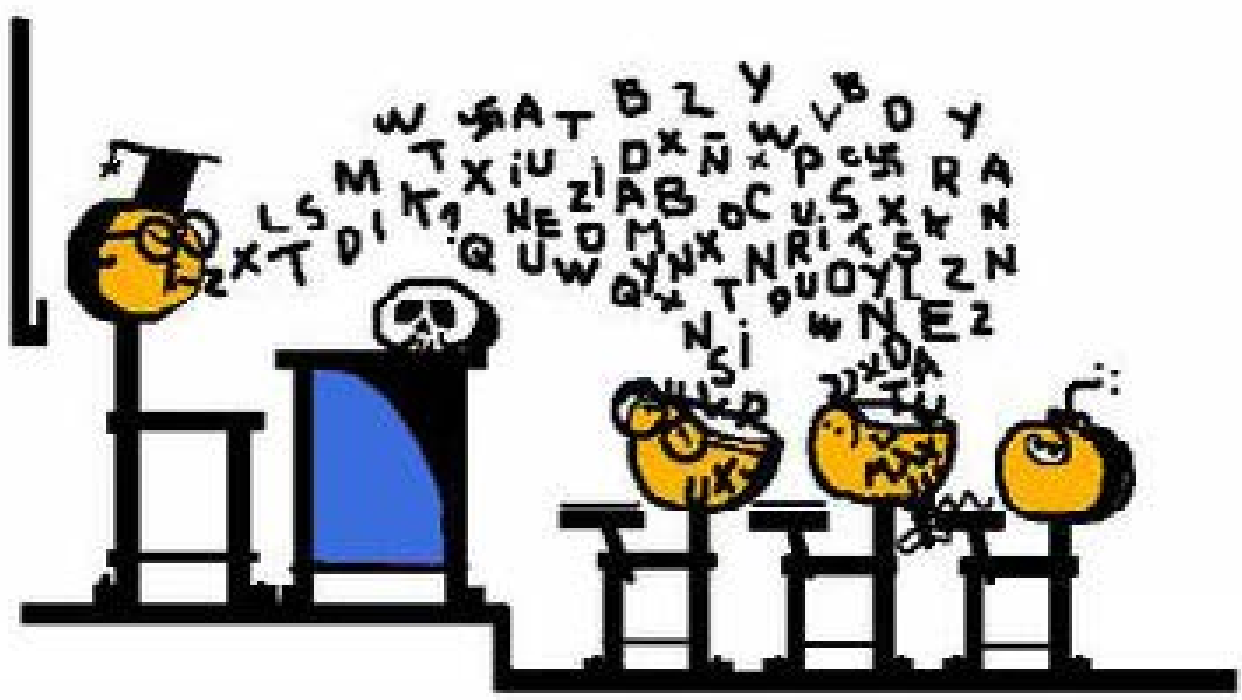

